\title{
A expansão dos Institutos Federais de Educação, Ciência e Tecnologia no território brasileiro: entre o local e o nacional
}

L'expansion des Instituts Fédérales d'Éducation, Science et Technologie sur le territoire brésilien : entre le local et le nationale

The Federal Institute of Education, Science and Technology expansion in Brazilian territory: between the local and the national

La expansión de los Institutos Federales de Educación, Ciencia y Tecnología en el territorio Brasilero: cuestiones entre lo nacional y lo local

\section{Fernanda Paixão de Souza Gouveia}

\section{(2) OpenEdition}

\section{Journals}

\section{Edição electrónica}

URL: http://journals.openedition.org/espacoeconomia/2434

DOI: $10.4000 /$ espacoeconomia.2434

ISSN: 2317-7837

\section{Editora}

Núcleo de Pesquisa Espaço \& Economia

\section{Refêrencia eletrónica}

Fernanda Paixão de Souza Gouveia, «A expansão dos Institutos Federais de Educação, Ciência e Tecnologia no território brasileiro: entre o local e o nacional », Espaço e Economia [Online], 9 | 2016, posto online no dia 19 janeiro 2017, consultado o 10 dezembro 2020. URL : http:// journals.openedition.org/espacoeconomia/2434; DOI : https://doi.org/10.4000/espacoeconomia. 2434

Este documento foi criado de forma automática no dia 10 dezembro 2020.

\section{c) (1) 8 (2)}

Espaço e Economia - Revista brasileira de geografia econômica est mise à disposition selon les termes de la licence Creative Commons Attribution - Pas d'Utilisation Commerciale - Partage dans les Mêmes Conditions 4.0 International. 


\title{
A expansão dos Institutos Federais de Educação, Ciência e Tecnologia no território brasileiro: entre o local e o nacional
}

\author{
L'expansion des Instituts Fédérales d'Éducation, Science et Technologie sur le \\ territoire brésilien : entre le local et le nationale \\ The Federal Institute of Education, Science and Technology expansion in \\ Brazilian territory: between the local and the national \\ La expansión de los Institutos Federales de Educación, Ciencia y Tecnología en el \\ territorio Brasilero: cuestiones entre lo nacional y lo local
}

Fernanda Paixão de Souza Gouveia

\section{Introdução}

1 Este artigo faz uma breve análise sobre o processo de expansão dos Institutos Federais de Educação, Ciência e Tecnologia (IFs) no território brasileiro tensionando a relação entre o desenvolvimento local e o nacional ${ }^{1}$. Desde o ano de 2003, a partir do governo de Lula da Silva, a Rede Federal de Educação Profissional, Científica e Tecnológica ${ }^{2}$ tem sofrido significativa ampliação fazendo-se presente em ambientes urbanos e interiorizados sob a lógica de que é necessário desenvolver o local para desenvolver o nacional. Mas ao observarmos as pesquisas sobre o processo de expansão dos IFs identificamos em primeiro, o baixo impacto tecnológico e extensivo destas instituições na realidade cotidiana local onde se instala, apesar de reconhecer a importância de sua oferta ao acesso à formação técnico-científica pelos sujeitos locais e circunvizinhos. Em segundo, que ainda a expansão se funda na lógica do papel formativo da escola para o atendimento mais imediato da indústria local, isso quando atende aos chamados arranjos produtivos locais que devem ser orientadores na criação dos cursos ofertados. 
Por último, por reforçar a nova histórica de dualidade educacional em que sob a aparente ampliação da escola subjazem escolas distintas, para classes distintas, que alimentam a ilusão de que se destina para todos, indistintamente (ALGEBAILE et al, 2013).

2 Dividimos nossas reflexões em dois momentos. No primeiro fazemos breve reflexões sobre o processo de expansão da Rede Federal, destacando que sua expansão tem muitos limites e materializam a dualidade da escola e o desenvolvimento desigual e combinado que nos caracteriza como nação e na concorrência capitalista. No segundo momento, apresentamos crítica à lógica da valorização do local em detrimento do global e nacional destacando a centralidade dos Arranjos Produtivos Locais (APLs) na orientação das políticas de educação profissional.

\title{
Reflexões sobre a expansão da Rede Federal
}

\author{
Os IFs em sua tessitura presente guardam a \\ natureza de relações sociais, econômicas, \\ culturais e políticas, que mediam essa modalidade \\ de ensino. As diferentes conjunturas, no que é \\ estrutural, mantêm o viés da negociação pelo alto \\ e sob um horizonte de projeto societário e de \\ desenvolvimento de natureza modernizante \\ conservadora. Ideário do progresso e da expansão \\ de fronteiras para, hoje, o grande capital \\ financeiro, industrial e do agronegócio e de \\ serviços (FRIGOTTO, 2015, p. 92).
}

3 O trecho acima expõe o contexto em que se insere a expansão recente da Rede Federal de Educação Profissional, Científica e Tecnológica (RFEPCT, doravante denominada Rede Federal). Apesar das várias contradições contidas em seu resultado, sua natureza é modernizante conservadora. Seu compromisso se vincula aos interesses mais imediatos do capital e, apesar de ampliar o acesso ao ensino profissional, mesmo que de forma dual, foi adentrando pelo território brasileiro.

4 Há consenso entre os pesquisadores que estudam tal expansão de que a nova institucionalidade e engenharia da educação profissional se concretizou a partir da Lei 11.892/20083 (ARAÚJO e HYPOLITO,2010; ARCARY, 2015; FRIGOTTO,2015; OTRANTO, 2010; SANTOS, 2015; entre outros). Os Institutos Federais de Educação, Ciência e Tecnologia (IFs) deram materialidade a este processo, que não só é institucional como também territorial, vale dizer (vide mapa 1). 
Mapa da expansão da Rede Federal pelo território brasileiro
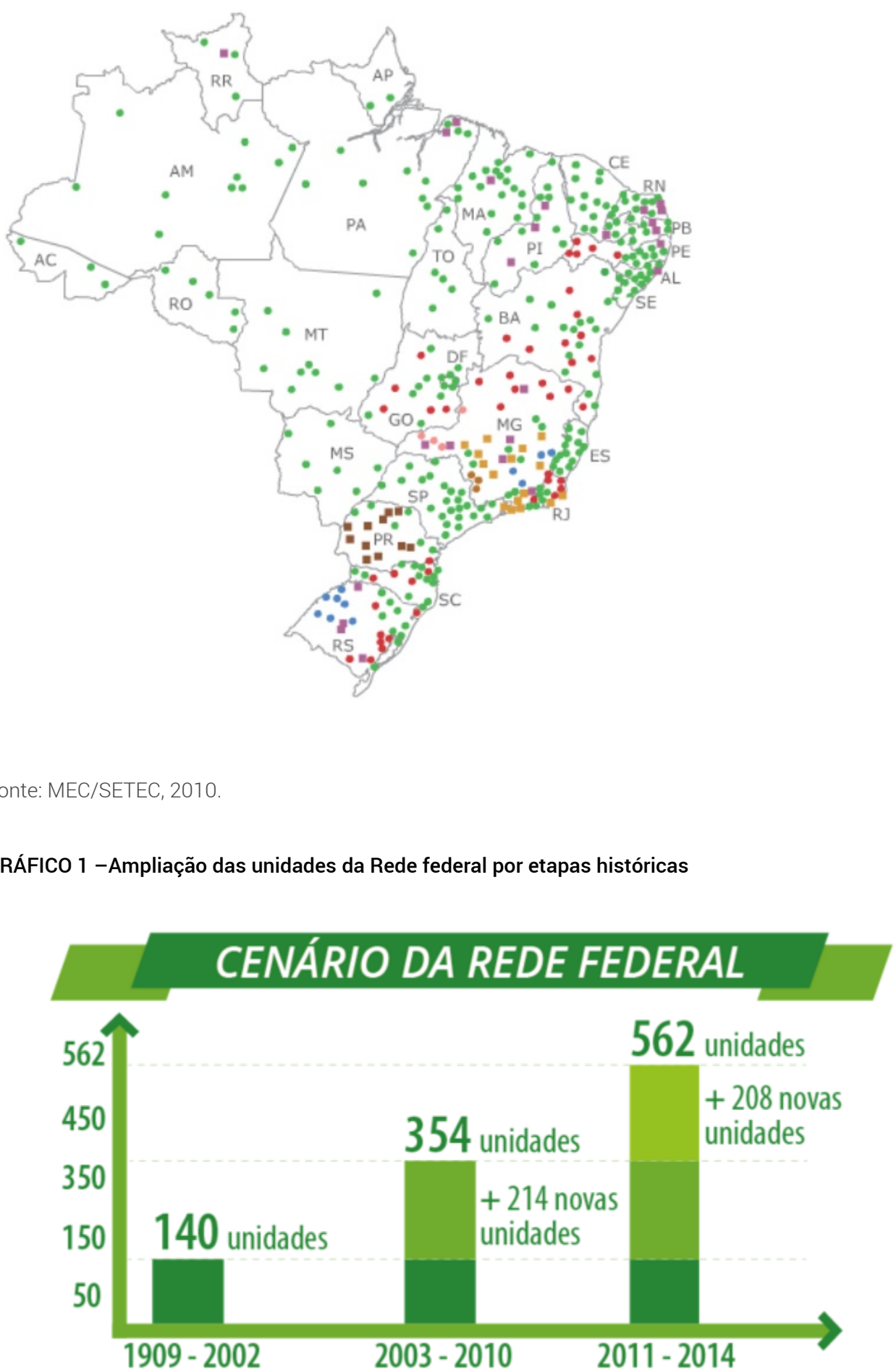

Fonte: MEC/SETEC, 2010

6 Conforme destaca Santos (2015, p. 107) os investimentos na Rede Federal saltaram de dois bilhões em 2003 para nove bilhões em uma década depois. Foi principalmente a partir do segundo mandato de Lula da Silva (2007-2010) que, em articulação com o projeto desenvolvimentista exposto em seu Plano Plurianual (2004-2007), que se identifica o deslocamento de unidades das escolas técnicas federais para o interior. Para 
Santos (2015, p.107) o processo de interiorização guarda forte presença da concepção cepalina fundada na ideia de diminuição das desigualdades regionais com a ampliação de oportunidades e acesso às experiências do mundo moderno.

GRÁFICO 2 - Despesas pelo MEC com a Rede Federais (2003-2013)

Em bilhões*

Despesas Realizadas pelo Ministério da Educação com a RFEPCT. Brasil. 2003 a 2013. (Em RS bilhões)*

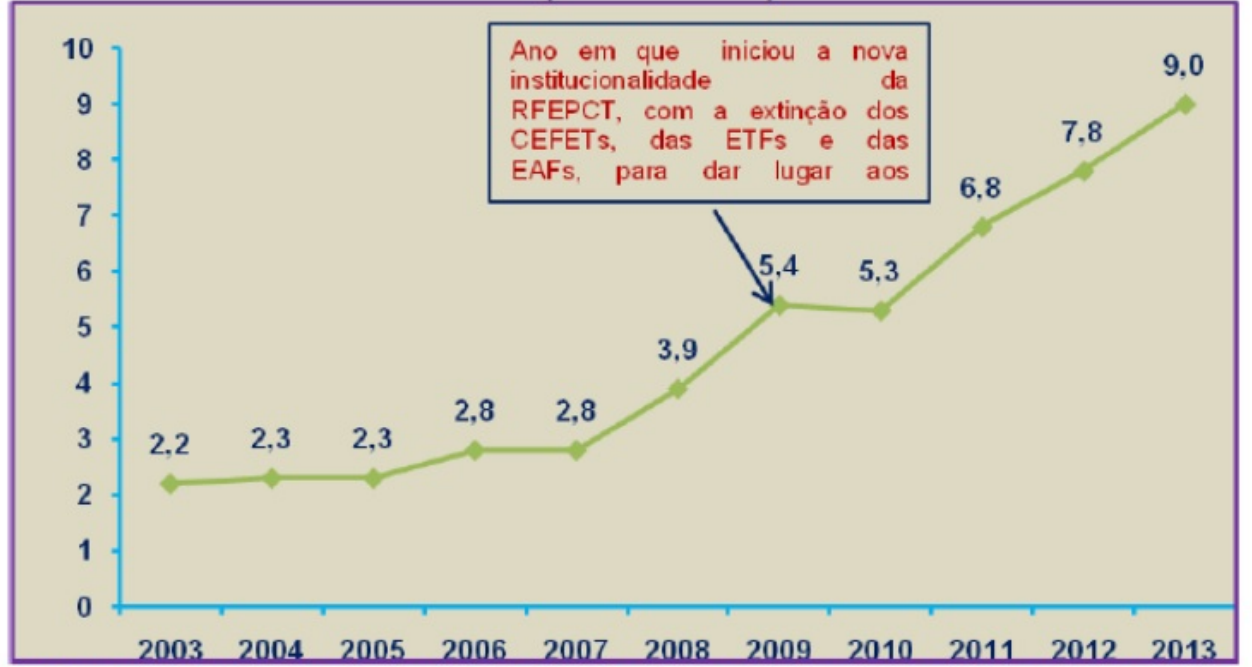

Fonte: Elaborado pelo autor a partir de dados constantes das Prestações de Contas da Presidência da República, referentes aos anos de 2003 até 2013.

*Nos valores do gráfico estão agregados o Orçamento Fiscal e o da Seguridade Social, e os mesmos foram deflacionados pelo IGP-DI/FGV a preços de fevereiro de 2015.

Fonte: Santos, 2015, p. 107

7 Corroboramos com Santos (2015) ao analisarmos a experiência da expansão e interiorização dos IFs e questionamos o discurso do governo federal que justifica a criação dos mesmos. A nosso ver, a despeito da oferta e acesso por setores mais pobres da sociedade à educação profissional pública e gratuita, há a existência de um projeto de modernização conservadora de abertura desta modalidade de educação e seu espraiamento pelo território nacional para o atendimento dos interesses mais imediatos do capital. Não é uma concessão ou se confunde com um projeto de inserção à cidadania emancipatória, pode e deve ser compreendida diante da necessidade de formar quadros para compreender a tecnologia científica que compõe o avanço da indústria.

8 Conforme indicam Harvey (2005) e Ferrão (2011) o âmbito local tem hoje papel central para o desenvolvimento do capital. Cada vez mais o capital necessita da aproximação com o local, é o que permite que os grupos de poder possam negociar em escala local superando as velhas amarras do empreendimento econômico e satisfazendo seus interesses. No caso do Brasil, esta negociação é garantida a partir da autonomia do ente federativo municipal, com poderes autárquicos, a partir da Constituição Federal de 1988.

9 Tal negociação se materializa também no âmbito educacional com a interferência dos grandes grupos econômicos privados nas políticas de educação. Esta é a tendência cada 
vez mais aberta e explícita que se coaduna com as orientações e recomendações dos organismos internacionais, expressões do momento capitalista-imperialista.

Sob a égide do capital monetário se instaura uma nova forma histórica de dualidade educacional, onde se democratiza o acesso à escola "a todos os níveis de certificação, mantendo-se a diferença qualitativa entre os percursos da classe trabalhadora e os das classes dominantes" (ALGEBAILE et al, 2013, p. 723). O acesso a diferentes formas de certificação, modalidades de ensino e espaços de formação que tradicionalmente não eram acessados pela classe trabalhadora mais pobre e seus filhos, ofuscam a manutenção de escolas distintas, social e estruturalmente duais, bem como alimentam a ilusão da qualidade social semelhante dos filhos da burguesia (ALGEBAILE et al, 2013).

11 A nosso ver, os IFs dão materialidade a este novo tipo de dualidade educacional e expressam os determinantes históricos que nos qualificam na condição de periferia e dependência do capitalismo. Frigotto retoma (2015, p. 88-89) o conceito de desenvolvimento desigual e combinado, debatido pela Sociologia brasileira dos anos 70, especificamente por Florestan Fernandes ${ }^{4}$, para entender nosso processo histórico e o alcance das políticas públicas de emprego, renda e formação profissional dos jovens da classe trabalhadora.

Opondo-se à perspectiva etapista-dualista hegemônica neste tempo, a intelectualidade crítica tenta superar a ideia de que o moderno pode constranger o arcaico e fazer avançar para o desenvolvimento nacional quando identifica a dialética da relação entre ambos (DEMIER, 2007). A essência combinada do moderno e do arcaico é característico do próprio desenvolvimento capitalista nos países de trajetória colonizada e tardia.

13 Isto significa dizer que as burguesias periféricas, tal como no Brasil, atreladas ao capital estrangeiro e aos interesses dos grandes proprietários rurais, foram incapazes de realizar a travessia democrática e construir um projeto de educação básica de concepção republicana (FRIGOTTO, 2015), contudo, foram bastante competentes para engendrar, como indica Demier (2007), estruturas de dominação sobre os subalternos e intensificar os privilégios de grupos.

14 A dualidade educacional de novo tipo debatida por Algebaile et al (2013) converge com a tese do desenvolvimento desigual e combinado onde se reconhece ser a manifestação histórica do antagonismo da relação capital-trabalho (ALGEBAILE et al, 2013, p. 735). A superação deste antagonismo está, para um significativo grupo de intelectuais da educação, no ensino integrado e nos ideais da politecnia. Neste contexto, a Rede Federal teria grande potencial de mudança.

15 Frigotto (2015) apesar de acreditar no potencial da Rede Federal o coloca em xeque frente ao processo de expansão, principalmente pela dificuldade de forjar uma (nova) identidade e pelos modelos alijados de oferta de educação profissional . Para ele, a criação dos IFs pode ser o início do desmantelamento do ensino médio ou mesmo da perda de sua prioridade, diz ele, apesar da Lei 11.892/2008 (BRASIL, 2008) garantir que $50 \%$ das vagas sejam direcionadas para este nível de ensino. "O curto tempo presente, em vários IFs, já demonstra essa tendência" (FRIGOTTO, 2015, p. 91). Há que se destacar a desconstrução da perspectiva da educação profissional com a eleição de cursos de curta duração e grande escala, tal como o PRONATEC ${ }^{5}$ representa.

16 A dificuldade de constituição de uma identidade real dos IFs também é um elemento que ameaça o ensino médio técnico ofertado tradicionalmente, seja qual for a modalidade em que for ofertado, diz Frigotto (2015). Diferentes grupos da Rede Federal 
passaram por diferentes institucionalidades e culturas (foram agrotécnicas, escolas técnicas, Cefets); diferentes gerações de servidores disputam na atualidade projetos de educação e poder político. Vale destacar mais uma vez as palavras deste autor:

[...] juntaram-se culturas muito diversas das agrotécnicas, colégios técnicos, com a dominância dos CEFETs da área industrial. No caso das agrotécnicas, em vários casos, tratava-se de feudos com poder cristalizado e com parco controle efetivo do Ministério da Educação (MEC) (FRIGOTTO, 2015, p.94).

17 No campo das contradições, o mesmo conjunto de intelectuais que elaboram a crítica a respeito da expansão da Rede Federal, principalmente por conta da precariedade infraestrutural que sustentam seu espraiamento e os efeitos sobre o modelo de ensino médio técnico, também se destaca o caráter progressivo que a expansão contém. Como negar que em um país com baixa escolaridade a expansão da Rede Federal e sua interiorização são positivas, mesmo que insuficiente ou precária? Mesmo assim, cabe uma advertência por Arcary: o atual formato que os IFs têm é tão complexo que a administração fica quase impossível (ARCARY, 2015, texto em $\mathrm{html}$ ).

Outras questões postas por Magalhães e Lima (2016) também carregam um tom de advertência: "Afinal de conta, para que(m) servem os Institutos Federais? Qual projeto de sociedade eles buscam atender? Responde a quais interesses de classe?" .

Os pesquisadores para além de criticar a lógica da precarização que rege o modelo de expansão da Rede Federal, onde destacam a falta de infraestrutura e a improvisação física e humana, reforçam que a concepção de educação contida nos IFs se relaciona aos interesses do capital na reprodução da lógica do empreendedorismo e da empregabilidade contida em seus projetos pedagógicos de cursos sob a primazia das competências.

20 Também há sintonia dos interesses do capital com o modelo expansão que leva em conta o perfil econômico das variadas regiões do país, acabando por reproduzir as assimetrias regionais ao priorizar como critério da expansão os arranjos produtivos locais $^{6}$ (APLs).

21 A este respeito cabe crítica a respeito do potencial dos IFs para o desenvolvimento local e a transferência de conhecimento, conteúdo presente de forma clara nos objetivos e finalidades ${ }^{7}$ que explicam sua criação. Em pesquisa recente ${ }^{8}$ da Fundação Joaquim Nabuco, coordenada pelo pesquisador Adriano Baptista Dias, chegou-se a conclusão que a maioria dos IFs não realiza pesquisa que contribuam para a realidade local. A explicação para essa ausência está na própria precarização do modelo de expansão: no tripé ensino, pesquisa e extensão comprometido com as extensas horas de trabalho do professor quase que exclusivamente na sala de aula, nos deficientes laboratórios e infraestrutura em geral, na falta de material humano, no atendimento de diferentes níveis e modalidades de ensino que tornam complexo o trabalho dos profissionais da educação, no pouco diálogo das instituições com a localidade em que está implantado, nos acordos de instalação de campi baseados que respondem aos interesses da municipalidade, entre outros. Todo este conjunto de questões citados (poderíamos citar outros) levam os pesquisadores a concluírem que os IFs não promovem a inovação nem contribuem para a redução das disparidades regionais. A nosso ver, uma expressão do desenvolvimento desigual e combinado do capitalismo no Brasil.

A partir disso, retomemos as questões postas por Magalhães e Lima (2016): "Afinal de conta, para que $(\mathrm{m})$ servem os Institutos Federais? Qual projeto de sociedade eles 
buscam atender? Responde a quais interesses de classe?". As respostas se voltam para a reflexão sobre o modelo burguês do Estado brasileiro.

Busquemos a ajuda de Poulantzas (2000) ao descrever o Estado burguês como um processo social e como uma condensação material da disputa entre as classes e frações da sociedade. As classes de poder precisam se assegurar que no processo de disputa com os explorados tenham um aparato que lhes permita unificar os seus interesses com os interesses populares, de forma a fazer com que os explorados consintam com projeto burguês de sociabilidade. Dessa forma, o Estado cumpre um papel de representação classista e a dominação política vai depender da capacidade das classes de poder de promover seu projeto hegemônico, vale dizer, projeto este passível de ser questionado pelos explorados por meio de sua luta social.

24 Agambem (2004) e Wacquant (2011) ao analisarem as atitudes do Estado neoliberal por meio das políticas públicas expõem as formas de exceção praticadas pelo Estado brasileiro, seja na lógica do Estado penal ou da política indeterminada - entre a democracia e o absolutismo (AGAMBEM, 2004, p. 13) nos ajudam a compreender como este Estado legisla para a manutenção da exclusão social. Os mecanismos de exceção servem para que se impeça que os explorados da classe trabalhadora não possam ter acesso ao que é seu por direito e de forma igualitária. 0 acesso à escola é uma expressão disso em sua dualidade estrutural, renovada também pelo processo de expansão da Rede Federal.

Mais uma vez recorremos à Algebaile et ali (2013, p. 725) cuja análise também é valida para os IFs:

[...] quantidade e variedade não significam oferta ampla, mas sim pulverizada, desigual, irregular e instável. Isso se evidencia, entre outros aspectos, no perfil formativo dos variados programas, que pode pender para a reinserção escolar, a complementação da escolaridade, a qualificação profissional, a formação cívica ou a formação atitudinal, entre outros vieses formativos cujos sentidos verdadeiros só são apreensíveis se levarmos em conta o efeito de conjunto dessa variedade de ações instáveis e orgânicas à lógica da forte fragmentação do trabalho e do imprescindível controle social.

O caráter classista é encoberto pelo discurso inclusivo. A este respeito Neves (2005) traz contribuições valiosas quando aponta que as condições e contradições recentes do modelo capitalista exigem novo rearranjo social e político que faz emergir um novo bloco histórico e nova relação pedagógica entre o Estado e a sociedade com novos códigos e padrões de sociabilidade. Diz Neves (2005) que o Estado neoliberal atualiza sua pedagogia da hegemonia ${ }^{9}$ com ações concretas em sua aparelhagem estatal e na sociedade civil. o discurso da inclusão social compõe a materialidade dessa nova relação e expõe clara da subordinação da política educacional aos interesses dos grandes grupos econômicos privados:

Sob a hegemonia burguesa, o Estado capitalista vem realizando a adaptação do conjunto da sociedade a uma forma particular de civilização, de cultura e moralidade [...] vem redefinindo suas diretrizes e práticas, com o intuito de reajustar suas práticas educativas às necessidades de adaptação do homem individual e coletivo aos novos requerimentos do desenvolvimento do capitalismo monopolista (NEVES, 2005, p. 26). 


\section{Crítica à predominância do local em detrimento do global e das escalas intermediárias}

27 Conforme Art. $7^{\circ}$ da Lei $n^{\circ}$ 11.892/2008 (BRASIL, 2008), os Institutos Federais têm por finalidades e características: a oferta de Educação Profissional em todos os níveis de ensino e modalidades, de forma a permitir o desenvolvimento socioeconômico do local ao nacional; o desenvolvimento da Educação Profissional e tecnológica como um processo educativo e investigativo que corresponda às demandas sociais e regionais, principalmente orientando a oferta formativa para o fortalecimento dos arranjos produtivos, sociais e culturais locais; a otimização material das instituições por meio da integração e da verticalização da Educação Básica à Educação Profissional e Educação Superior; constituir-se como centros de excelência e referência às outras instituições públicas; o estímulo à pesquisa aplicada, à produção cultural, ao empreendedorismo, ao cooperativismo, a atividades de extensão, bem como promover tecnologias sociais voltadas para a preservação do meio ambiente. Tais finalidades revelam o papel modelar que os Institutos Federais passam a assumir no desenvolvimento da Educação Profissional, o que ratificaria, na visão do MEC, a condição de centros de excelência e referência para demais instituições de Educação Profissional do país (BRASIL, 2008).

28 De fato, os Institutos Federais deram materialidade a um novo modelo de gestão educacional no atendimento da Educação Básica, superior e profissional em diferentes modalidades de ensino. Segundo o discurso oficial, trata-se de um modelo reconhecido por sua modernidade e experiências bem sucedidas na condução da Educação Profissional brasileira. Apesar do ufanismo deste discurso, não podemos negar que a nova estruturação da Rede Federal apresenta grandes perspectivas de desenvolvimento no país de mais oportunidades de acesso a um leque bastante diverso e flexível de formação para o trabalho. Isto coaduna com os interesses do mercado, conforme recomendação dos organismos internacionais como o Banco Mundial.

Considerando, portanto, o crescimento expressivo do número de instituições federais de educação profissional e tecnológica com a expansão, as novas possibilidades de atuação e as propostas político-pedagógicas que surgem intrinsecamente desse processo em que o caráter social é preponderante, a necessidade de uma nova institucionalidade emerge. Em decorrência, a criação dos Institutos Federais de Educação, Ciência e Tecnologia representa a materialização deste novo projeto, reconhecendo-se como referendo do governo no sentido de colocar em maior destaque a educação profissional e tecnológica no seio da sociedade. Enfim, os Institutos Federais fundamentam-se em uma ação integrada e referenciada na ocupação e desenvolvimento do território, entendido como lugar de vida (SETEC/MEC, 2010, p. 15).

29 Contudo, nossa crítica se centra na supremacia dos arranjos produtivos locais como justificativa para a expansão dos IFs e base para o desenvolvimento do país. A despeito da importância dos IFs e seus impactos locais com oferta de escolarização, principalmente em regiões periféricas, sua justificativa de criação se sustenta na fragilidade da perspectiva do localismo como alternativa para o avanço e desenvolvimento nacional, sem as escalas intermediárias defendidas por Brandão (2007).

30 Castro (2011) ao estudar as operárias costureiras de Friburgo, no Rio de Janeiro, recupera o processo de desenvolvimento da ideia dos arranjos produtivos locais como estruturante da reestruturação produtiva brasileira. Para nós, tal ideia se faz 
importante, por ser tratar de um dos elementos centrais para justificativa da expansão dos IFs na intervenção e inter-relação na/com realidade local.

Comenta Castro (2011, p.15) que a experiência da criação do Polo de Moda Íntima de Friburgo no final dos anos 90, caracterizado por ele como um projeto político da Federação das Indústrias do Estado do Rio de Janeiro (Firjan) e da classe burguesa local, em correspondência às estratégias da Associação Brasileira de Indústrias Têxteis (Abit), foi incorporada ao projeto-piloto do governo federal, na gestão de Fernando Henrique Cardoso (FHC), de integração econômica inspirado nos distritos industriais marshalianos ${ }^{10}$.

O governo Lula da Silva (2003-2010) deu continuidade ao projeto de desenvolvimento do governo anterior de investimento nos arranjos produtivos locais, sendo o tema incorporado nos Planos Plurianuais e também na Política de Desenvolvimento Produtivo (PDP) de 2008. O objetivo seria o de "fortalecer as cadeias produtivas, incentivar a cooperação dentro delas, aperfeiçoar as redes e arranjos produtivos locais, desenvolver produtos de maior valor agregado e expandir exportações", conforme destaca Castro (2011, p. 70).

Contudo, ao avaliar os efeitos destas ações sobre a realidade friburguense, Castro faz dura crítica aos seus impactos na dinâmica do trabalho das costureiras e consequente ampliação da exploração destas trabalhadoras. Afirma que tais políticas tinham como principal objetivo "conectar o regime de exploração local ao atual regime de acumulação. Ao mesmo tempo em que empresas domésticas foram transformando-se em indústrias, houve um contínuo aumento de trabalhadoras em domicílio e de facções, com a manutenção de salários baixos" (CASTRO, 2011, p. 70).

34 A análise de Castro (2011) nos remete à reflexão sobre os objetivos e fins de implantação dos IFs no território nacional. Na tabela abaixo, ficam explícitos os critérios que justificam cada uma das três fases de expansão. Nas duas primeiras fases consta a preocupação com a proximidade e sintonia dos IFs com os arranjos produtivos locais, deixando clara a necessidade da formação de mão-de-obra para atender às indústrias próximas à instalação dos campi.

35 Também fica clara a dependência do projeto de expansão dos IFs às parcerias locais que nem sempre consegue atender às diretrizes presentes na primeira fase, quais sejam, estar presente onde não havia escolas federais, distante principalmente dos centros econômicos. Se tomarmos o Rio de Janeiro como referência, vemos que muitos campi ficam próximos aos grandes centros, desrespeitando por vezes a orientação de distância mínima de $50 \mathrm{Km}$ entre os campi prevista na segunda fase.

Esta constatação acaba por salientar as assimetrias regionais já existentes na trajetória histórica de ocupação territorial e desenvolvimento socioeconômico brasileiro e expõem que muitos outros interesses definem onde devem ser instalados os campi. As parcerias muitas vezes não se comprometem com o fato que é de grande importância para a permanência dos discentes que adentram aos portões destas instituições federais, a garantia, por exemplo, do passe livre para todos os alunos da Educação Básica ${ }^{11}$. 
Tabela 1 - Critérios de escolha dos lugares dos novos campi por fase da expansão

\begin{tabular}{|c|c|}
\hline $\begin{array}{l}\text { Fases da } \\
\text { Expansão }\end{array}$ & Critérios \\
\hline $\begin{array}{l}\text { Fase I (2003 } \\
\text { a 2010) }\end{array}$ & $\begin{array}{l}\text { a) Proximidade da escola aos arranjos produtivos instalados em níveis local e } \\
\text { regional (grifo nosso); } \\
\text { b) Importância do município para a microrregião da qual faz parte; } \\
\text { c) Valores assumidos pelos indicadores educacionais e de desenvolvimento } \\
\text { socioeconômico; } \\
\text { d) Existência de potenciais parcerias para a implantação da futura unidade; } \\
\text { e) Atender a pelo menos uma das três seguintes diretrizes: e.1) estar localizada em } \\
\text { uma Unidade da Federação que ainda não possui instituições federais de educação } \\
\text { profissional e tecnológica instaladas em seu território; e.2) estar localizada em } \\
\text { alguma das regiões mais distantes dos principais centros de formação de mão de } \\
\text { obra especializada; e.3) nos casos em que o município selecionado pertencer a uma } \\
\text { região metropolitana, a escola deverá estar situada nas áreas de periferia. }\end{array}$ \\
\hline $\begin{array}{l}\text { Fase II } \\
(2011 / 2012)\end{array}$ & $\begin{array}{l}\text { a) Distribuição equilibrada das novas unidades (distância mínima de } 50 \text { km entre os } \\
\text { novos campi); } \\
\text { b) Cobertura do maior número possível de mesorregiões; } \\
\text { c) Sintonia com os arranjos produtivos locais (grifo nosso); } \\
\text { d) Aproveitamento de infraestrutura física existente; } \\
\text { e) Identificação de potenciais parcerias. }\end{array}$ \\
\hline $\begin{array}{l}\text { Fase III } \\
(2013 / 2014)\end{array}$ & $\begin{array}{l}\text { a) População dos Estados em relação à população total do Brasil; } \\
\text { b) Presença das redes federal e estadual de educação profissional tecnológica nos } \\
\text { Estados (esta última apoiada pelo Programa Brasil Profissionalizado); } \\
\text { c) Índice de Desenvolvimento da Educação Básica (IDEB) de cada Estado; } \\
\text { d) Jovens de } 15 \text { a } 24 \text { anos cursando os últimos anos do ensino fundamental (6oo ao } 9^{\circ} \\
\text { ano) em relação à população jovem do Estado; } \\
\text { e) Número de mesorregiões e municípios presentes em cada unidade da Federação. }\end{array}$ \\
\hline
\end{tabular}

Fonte: Fonte SETEC/MEC apud TCU ( 2012, p. 6-7).

37 O tema da relação dos IFs com o setor produtivo local foi tema presente no Relatório do Tribunal de Contas da União (TCU, 2012). Destaca, o TCU que os IFs devem interagir com o setor produtivo local a partir do tripé do ensino, pesquisa e extensão (2012,p. 20), conforme prevê sua lei de criação. Há certo consenso nas análises do TCU de que a escolha dos cursos dos campi instalados converge para as demandas locais, contudo, a convergência se encerra muitas vezes nesta etapa já que a pesquisa e a extensão dificilmente são desenvolvidas ${ }^{12}$. Para o TCU, tal condição se explica por questões de caráter burocrático, nas dificuldades de estabelecer parcerias devido à condição complexa que possuem os IFs, bem como conhecimento das bases legais e dos instrumentos jurídicos para formalização dessas parcerias. Esta condição coloca sob ameaça o projeto da expansão no que diz respeito ao seu objetivo de contribuir para o desenvolvimento socioeconômico local, regional e nacional por meio da difusão dos conhecimentos científicos e tecnológicos. 
Uma característica do processo de interiorização que traz grandes desafios para a atuação dos campi é o peso relativo do setor público nas economias locais. As microrregiões de menor nível atividade econômica também são aquelas mais dependentes do setor público, com os outros setores da economia bastante debilitados. [...] Nesses locais, há o risco da atuação dos Institutos Federais não encontrar uma estrutura produtiva suficientemente dinâmica para receber seus produtos, seja a mão de obra formada, sejam as parcerias de pesquisa e extensão. A superação desse e de outros obstáculos dependerá de uma maior convergência de esforços com o setor público local e o enfraquecido setor produtivo (TCU, 2012, p. 23).

Sendo repetitivos, de forma proposital, recolocamos a pergunta de Magalhães e Lima (2016) apenas para o retorno da reflexão: nas condições rebaixadas expostas nas pesquisas e no relatório do TCU, "Para que (m) servem os institutos federais?".

Um dos desafios destacados pelo TCU na expansão seria que quando instalados em municípios mais dinâmicos economicamente e menos dependente de recursos públicos de uma microrregião, pouco dialogam com as regiões vizinhas que ele também atende, pois seus alunos e servidores ali habitam e se deslocam. A nosso ver, um maior diálogo entre estas regiões poderiam resolver problemas práticos, não menos importantes, para permanência dos educandos nos campi instalados. Contudo, não resolvem as questões estruturais que na verdade compõe o modelo de desenvolvimento de um país de cariz dependente. Partindo de Brandão (2007), é um grande equívoco acreditar que o local possa resolver os problemas que são de ordem nacional/global.

É preciso discutir a espacialidade dos problemas e implementar políticas levando em consideração a escala específica desses problemas, mas em um contexto em que esteja presente um projeto nacional de desenvolvimento. Penso que, ao contrário daquelas visões, as escalas "intermediárias" ganham novo sentido e importância nessa fase do capitalismo. (itálicos do autor) (BRANDÃO, 2007, p. 36)

- A supremacia do localismo pela via da supervalorização dos arranjos produtivos locais, negligenciam os fatores que são exógenos ao âmbito local, como as hierarquias, a macroeconomia, as distintas formas de poder (BRANDÃO, 2007). Assim como Harvey (2005), Brandão vai à história para encontrar elementos para superar a extremada visão localista de desenvolvimento. Compreende que a produção social do espaço, historicamente determinada e produto de correlação das forças sociais, deve ter por categoria explicativa a divisão social do trabalho "que permeia todos os seus processos, em todas as escalas" (BRANDÃO, 2007, p. 69).

Não ignoramos o poder local, muito menos sua capacidade de organização da sociedade para resolver seus problemas no âmbito da municipalidade, por exemplo. Mas as políticas de desenvolvimento não se encerram no local, dele precisam transcender estabelecendo nexos com os objetivos nacionais.

É o Estado educador de Neves (2005) que sob a égide do neoliberalismo incentiva à busca por soluções de questões da sociedade no âmbito local, construindo a falsa a ideia do desenvolvimento nacional a partir do local e estimulando, perversamente, a competitividade intercidades ou de interregiões, cujos laços históricos de cooperação e solidariedade são desmobilizados. A nosso ver, este Estado educador em seu projeto ignora que:

[...] o propalado poder local não conta com as prerrogativas necessárias à formulação e execução de uma política de desenvolvimento, que são os instrumentos básicos da política econômica - o comando sobre a taxa de juros, de câmbio, do crédito e da fiscalidade necessária (BRANDÃo, 2007, p.25). 
43 As alternativas de luta ao projeto neoliberal são pensadas por Brandão (2007). Na contramão do localismo exagerado, ações nacionais. Contra o distanciamento da escala local e nacional, as escalas intermediárias. A heterogeneidade brasileira, sua marca desigual e combinada, precisa ser levadas em conta na produção de um projeto nacional de desenvolvimento. As diferenças regionais não são nosso problema, mas nossa potência.

O Estado pode intervir para dinamizar a economia dos territórios sem agredir suas identidades e a potente variedade brasileira, estimulando proposta que vêm de baixo para cima, mas articulando-as numa política em escala nacional. Isso é fundamental. È fundamental evitar o localismo exagerado, que pode intensificar muitos desajustes sociais no país, propondo ações nacionais (BRANDÃo, 2007, p. 31).

Os IFs assumiriam importante papel se articulados a um projeto real de desenvolvimento nacional de superação das desigualdades sociais e assimetrias regionais. Mas sua difícil construção identitária, suas frágeis parcerias e objetivos não alcançados demonstram outra vez nossa condição periférica frente à divisão social do trabalho. Vale dizer, como destaca mais uma vez Brandão (2007, p. 69), esta é a categoria mediadora capaz de nos fazer compreender nossa heterogeneidade, as hierarquias e as especializações que estão dentro e entre as escalas cada vez mais manejadas pelo capital mundializado para suprimir as tentativas de projetos coletivos e universais.

Diante disso, no âmbito do projeto educacional brasileiro recentes que representa a criação e expansão dos IFs, perguntamos mais uma vez a quem "eles" servem e a qual projeto de sociedade e realidade busca atender? Dizemos ser um projeto classista que, permeado de contradições, está comprometido com a lógica do Estado educador neoliberal e com a ilusão da inclusão e integração social.

46 Alves (2013, texto em html) nos dá algumas indicações quando analisa o precariado e sua educação. Segundo este autor, instituições de ensino, tal como os IFs e as universidades públicas, formam cada vez mais uma camada média do proletariado altamente escolarizada que se insere de forma precária no mercado de trabalho e na vida social.

47 Sob a vigência de um novo mercado de trabalho de dinâmica financeirizada que não tem como incluir a todos, mesmo os bem qualificados, caberá ao Estado educador acionar estratégias que convençam a juventude desempregada e toda a classe trabalhadora de que é possível equilibrar bem-estar, direitos e mundo financeirizado.

Alves (2013) comenta que as universidades públicas e privadas cresceram $110 \%$ em uma década e dobrou seu número de formados. Tornam-se assim, incubadoras do precariado (ALVES, 2013). Um precariado educado pela lógica da acumulação flexível , cuja subjetividade vem sendo capturada (ALVES, 2000) e sonhos tornados suspensos. Jovens que validam a perspectiva do capital humano e a empregabilidade, com "trajetórias ocupacionais intermitentes, liminarmente precárias" (ALVES, 2013, texto em html). Mas que também reage, afinal o capital não controla todas as contradições que dele emergem.

49 À título de conclusão, a criação e expansão dos IFs vem servindo ao capital e ao seu projeto de conformação social. Forma quadros especializados, qualificados, para o trabalho e vida social precários. Conecta, assim como o faz com as costureiras friburguenses, o regime de exploração local com o atual regime de acumulação. Apesar 
de trazer mudanças pontuais para a realidade social local, estas ainda são insuficientes para a transformação em escala nacional.

Mais uma vez recorremos a Brandão quando o mesmo afirma que é preciso " construir nova hegemonia a partir do desmonte contínuo do pacto conservador de dominação interna, presente em qualquer escala espacial, inclusive nas menores" (BRANDÃO, 2007, p. 217). Contudo, o projeto de expansão dos IFs não representa a contra-hegemonia.

\section{BIBLIOGRAFIA}

AGAMBEN, G. Estado de exceção. São Paulo: Boitempo, 2004.

ALGEBAILE, E.; RUMMERT, S. Mª; VENTURA, J. Educação da classe trabalhadora brasileira: expressão do desenvolvimento desigual e combinado. Revista Brasileira de Educação (Impresso), v. 18, p. 717-738, 2013.

ALVES, G. $O$ que é o precariado? 22/07/2013. Disponível em: <http://blogdaboitempo.com.br/ 2013/07/22/o-que-e-o-precariado/>. Acesso em janeiro de 2016.

. Novo e precário mundo do trabalho. São Paulo: Boitempo, 2000.

A educação do precariado. 17/12/2012. Disponível em: <http://

blogdaboitempo.com.br/2012/12/17/a-educacao-do-precariado/. Acesso em janeiro de 2016.

ARAÚJO, Jair Jonko; HYPOLITO, Álvaro Moreira. Institutos Federais de Educação, Ciência e Tecnologia: Inovações e Continuidades. ANPED: 2010, p. 1-13. Disponível em <www.anped.org.br/33encontro/app/webroot/files/.../GT05-6449--Res.pdf>. Acesso em 20 de janeiro de 2011.

ARCARY, V. Uma nota sobre os Institutos Federais em perspectiva histórica. 2015. Disponível em: https://sinasefeifpr.wordpress.com/tag/ifs/.

BRANDÃO, Carlos. Território e desenvolvimento: as múltiplas escalas entre o local e o global. São Paulo, Campinas: Editora Unicamp, 2007.

BRASIL. Ministério da Educação. (2005). Plano de Expansão da Rede Federal de Educação Tecnológica. Brasília/DF: SETEC/MEC.

SETEC/MEC. Um novo modelo em educação profissional e tecnológica. Concepção e Diretrizes. 2010. Disponível em: < http://portal.mec.gov.br/index.php? option=com_docman\&view=download\&alias=6691-if-concepcaoediretrizes\&category _slug=setembro-2010-pdf\& Itemid=30192>. Acesso em janeiro de 2016.

Lei n¹1.892 de 28 de dezembro de 2008. Dispõe sobre a criação dos Institutos Federais de Educação, Ciência e Tecnologia. Disponível em: <http: //www.planalto.gov.br/ ccivil_03/_ato2007-2010/2008/lei/l11892.htm>. Acesso em 10 de junho de 2010.

Lei no 12.513, de 26 de outubro de 2011. Institui o Programa Nacional de Acesso ao Ensino Técnico e Emprego (Pronatec) e dá outras providências. Disponível em: < http:// www.planalto.gov.br/ccivil_03/_ato2011-2014/2011/lei/l12513.htm>. Acesso em janeiro de 2016. 
Lei № 12.677, de 25 de junho de 2012. [Equipara o Colégio Pedro II aos Institutos federais]. Disponível em: <http://www.planalto.gov.br/ccivil_03/_Ato2011-2014/2012/Lei/ L12677.htm>. Acesso em fevereiro de 2016.

CASTRO, R.S. Resistência e colaboração na reestruturação produtiva. Uma análise das operárias costureiras de Nova Friburgo/RJ. 2011. Dissertação de mestrado. Universidade Estadual Paulista (Unesp). Marília, São Paulo.

DEMIER, F. A lei do desenvolvimento desigual e combinado de León Trotsky e a intelectualidade brasileira: breves comentários sobre uma relação pouco conhecida. Disponível em: < http://www.unicamp.br/cemarx/anais_v_coloquio_

arquivos/arquivos/comunicacoes/gt3/sessao3/Felipe_Demier.pdf>. 2007. Acesso em fevereiro de 2016.

FERNANDES, F. Sociedade de classes e subdesenvolvimento. São Paulo: Global, 2008.

FRIGOTTO, G. Os Institutos Federais de Educação, Ciência e Tecnologia: gênese e indeterminação da identidade e campo de disputas. In FRIGOTTO, G. (coord.geral). ofertas formativas e características regionais: A Educação Básica de nível médio no Estado do Rio de Janeiro. Relatório de Pesquisa apresentado à FAPERJ em julho de 2015, pp. 85-99.

HARVEY, David. Espaços de esperança. São Paulo: Loyola, 2004.

. A produção capitalista do espaço. São Paulo: Annablume, 2005.

MAGALHÃES, G.; Lima, R. Para que(m) servem os institutos federais? Disponível em: <http:// pcb.org.br/portal2/9148>. Acesso em janeiro de 2016.

MELO, Ana Isabel. Distritos industriais marshallianos: o caso de águeda. s/d. Disponível em: < http://www.apdr.pt/siterper/numeros/RPER12/art02_rper12.pdf >. Acesso em fevereiro de 2016.

NEVES, L. M. W; SANT'ANNA, R. Introdução: Gramsci, o Estado educador e a nova pedagogia da hegemonia. In NEVES, L. M. W (org.). A nova pedagogia da hegemonia. Estratégias do capital para educar o consenso. São Paulo: Xamã, 2005, pp. 19-40.

OBAPL. OBSERVATÓRIO APL. O que são arranjos produtivos locais?. Disponível em: <http:// portalapl.ibict.br/menu/itens_menu/apls/apl_o_que_sao.html>. Acesso em fevereiro de 2016.

OTRANTO, Célia Regina. Criação dos Institutos Federais de Educação, Ciência e Tecnologia. In Retta. Seropédica, RJ: EDUR, 2010, vol. 1, n.1, pp. 89-108.

POULANTZAS, Nicos. 0 Estado, o poder, o socialismo. São Paulo: Paz e Terra. 2000.

SANTOS, J.A política de expansão da Rede Federal de Educação Profissional, Científica e Tecnológica: quais são as perspectivas para a nova territorialidade e para a nova institucionalidade? In FRIGOTTO, G. (coord.geral). Ofertas formativas e características regionais: A Educação Básica de nível médio no Estado do Rio de Janeiro. Relatório de Pesquisa apresentado à FAPERJ em julho de 2015, pp. 100-112.

SAVIANI, D. o lugar da educação no desenvolvimento nacional. [Texto de intervenção na mesa "Concepções de Desenvolvimento e de Educação e o Papel do Estado no Brasil hoje: um balanço crítico" no âmbito do Seminário "Desenvolvimento e Educação: qual Desenvolvimento e Educação para qual Sociedade?". Rio de Janeiro, UERJ, 18 de novembro de 2010]. Disponível em: <https:// www.google.com.br/url?sa=

t\&rct=j\&q=\&esrc=s\&source=web\&cd=3\&cad=rja\&uact=8\&ved=0ahUKEwj1o_TKlPHKAhUFh5AKHRnaDXgQFggoMAI\&url=http\%3A\%2F\%2 gMir 
YeS1320wC_Rs8HODnckA\&bvm=bv.113943164,d.Y2I>. Acesso em janeiro de 2016.

SOUZA, M. Maioria dos institutos federais não faz pesquisa tecnológica, diz estudo. 04/01/2016. Disponível em: < http://educacao.uol.com.br/noticias/2016/01/04/

maioria-dos-institutos-federais-nao-faz-pesquisa-tecnologica-diz-estudo.htm>. Acesso em janeiro de 2016.

TCU. Tribunal de Contas da União. Relatório de auditoria. Rede Federal de Educação Profissional, Científica e Tecnológica. Brasília, junho de 2012. Disponível em: < http:// portal.tcu.gov.br/lumis/portal/file/fileDownload.jsp?

inline=1\&fileId=8A8182A14D92792C014D92847E5F3E97 >. Acesso em dezembro de 2015.

WACQUANT, L. As prisões da miséria. Rio de Janeiro: Zahar, 2011.

\section{NOTAS}

1. A ênfase na tensão local e nacional não ignora a interação dinâmica entre os planos escalares, bem como compreende que estas escalas são mediadas por determinações históricas no plano do capitalismo internacional. Tendo por referência Harvey $(2004,2005)$ e observando a atual fase de globalização neoliberal com impactos sobre a produção social do espaço e o desenvolvimento geográfico desigual, compreendemos que as espacializações do capital ocorrem nas mais diferentes escalas (global, nacional, regional, local) e nos permite compreender as lutas de classes nessas mesmas escalas. $O$ capital se globaliza e a luta de classes também. A produção capitalista do espaço é erigida no processo dialético entre as escalas geográficas.

2. No âmbito do sistema federal de ensino, a Rede Federal de Educação Profissional, Científica e Tecnológica, vinculada ao Ministério da Educação é constituída pelas seguintes instituições: Institutos Federais de Educação, Ciência e Tecnologia (criados a partir da Lei 11892/2008), Centros Federais de Educação Tecnológica, Escolas Técnicas Vinculadas às Universidades Federais, Universidade Tecnológica Federal do Paraná, Colégio Pedro II.

3. Lei que cria os 38 Institutos Federais de Educação, Ciência e Tecnologia. que somados à Universidade Tecnológica Federal do Paraná (UTFPR), aos Centros Federais de Educação Tecnológica do Rio de Janeiro e de Minas Gerais (CEFET-RJ e CEFET-MG, respectivamente) e às Escolas Técnicas Vinculadas às Universidades Federais (EV) integralizam este novo arranjo institucional da educação federal profissional e pública (BRASIL, 2008, texto em html). Dados do reordenamento da Rede Federal fornecidos pelo Ministério da Educação (MEC), informam que 31 CEFET, 75 Unidades Descentralizadas de Ensino (UNED), 39 Escolas Agrotécnicas Federais (EAF), 07 Escolas Técnicas Federais (ETF) e 08 EV deixaram de existir para formar os Institutos Federais. O Colégio Pedro II, por meio da Lei 12.677/2012, são equiparados aos IFs e passam a ter a mesma estrutura e organização.

4. São obras de referência importantes para este debate em Florestan: A sociedade de classes e subdesenvolvimento (1968), Capitalismo dependente e classes sociais na América Latina (1973) e Revolução burguesa no Brasil (1975).

5. Programa Nacional de Acesso ao Ensino Técnico e Emprego. Criado em pela Lei 12.513/2011. A ser executado pela União apresenta como finalidade "ampliar a oferta de educação profissional e tecnológica, por meio de programas, projetos e ações de assistência técnica e financeira" (BRASIL, 2011).

6. “Arranjos produtivos locais são aglomerações territoriais de agentes econômicos, políticos e sociais - com foco em um conjunto específico de atividades econômicas - que apresentam vínculos mesmo que incipientes. Geralmente envolvem a participação e a interação de empresas que podem ser desde produtoras de bens e serviços finais até fornecedoras de insumos e 
equipamentos, prestadoras de consultoria e serviços, comercializadoras, clientes, entre outros - e suas variadas formas de representação e associação. Incluem também diversas outras organizações públicas e privadas voltadas para: formação e capacitação de recursos humanos, como escolas técnicas e universidades; pesquisa, desenvolvimento e engenharia; política, promoção e financiamento" (OBAPL, 2016).

7. A lei $11.892 / 2008$ que cria os IFs apresenta em suas finalidades, características e objetivos a relação das instituições com o lugar por meio da extensão e da interação com o conhecimento científico aplicado. Dessa forma, é marca da expansão em seu conteúdo legal é o fortalecimento local por meio da transferência de conhecimento e técnica.

8. A sistematização da pesquisa ainda não foi publicada. Ver reportagem disponível em: <http:// educacao.uol.com.br/noticias/2016/01/04/maioria-dos-institutos-federais-nao-faz-pesquisatecnologica-diz-estudo.htm>.

9. Neves (2005, p. 27) assim denomina o conjunto de estratégias acionadas pelo Estado capitalista em sua aparelhagem para educar à aceitabilidade as classes dominadas em torno de um projeto burguês de sociabilidade. Contudo, uma vez dialética e conflituosa a sociedade de classes, também se desenvolvem pari passu espaços de contra-hegemonia que disputam e podem rupturas frente ao projeto hegemônico.

10. Grosso modo, se define por uma forma de organização produtiva industrial cunhado pelo economista inglês Alfred Marshall (1842-1924) e revisado e atualizado nos anos 70 por outros economistas, tal como Giacomo Becattini, frente à crise do fordismo. Melo (s/d) define os distritos marshallianos como uma "rede composta essencialmente por empresas de pequena e média dimensão, que encontra o seu expoente máximo em alguns territórios, onde se privilegiam a iniciativa local e a interação entre as empresas e entre estas e as instituições locais, sempre com fortes ligações ao meio local".

11. No IFRJ, por exemplo, os campi mais distantes enfrentam sérias dificuldades para que os alunos da Educação Básica sejam reconhecidos em seu direito de acessar o transporte público como qualquer aluno da rede estadual ou municipal, isto porque a legislação do passe livre no Rio de Janeiro, apesar dos avanços alcançados pelo movimento de estudantes, ainda tem brechas e inconclusões.

12. A esta conclusão chegou também a pesquisa da Fundação Joaquim Nabuco investigada por SOUZA (2016.) e já citada neste trabalho. Contudo, as questões burocráticas nesta pesquisa não destacam a estrutura complexa institucional como fator para não realizar a pesquisa e a extensão e sim a sobrecarga das atividades docentes que impedem a dedicação a outras atividades essenciais.

\section{RESUMOS}

Este artigo analisa o processo de expansão dos Institutos Federais de Educação, Ciência e Tecnologia (IFs) no território brasileiro tensionando a relação entre o desenvolvimento local e o nacional. o projeto de expansão dos Institutos Federais erige-se na proposta de desenvolvimento socioeconômico do local para o nacional, comprometendo-se com o crescimento regional ao atender às demandas sociais locais por meio da oferta de formação profissional e tecnológica. Indicamos, contudo, que a supervalorização do local, que tem recebido cada vez mais atenção do capital, negligencia fatores que são exógenos a este âmbito, como as hierarquias, a 
macroeconomia e as distintas formas de poder, o que influencia no descumprimento da promessa central deste processo de expansão.

A partir de la tension entre le dévellopement local et le dévellopement nationale, cet article analyse l'expansions des Instituts Fédérales d'Éducation, Science et Technologie sur le territoire brésilien. Responsables pour la formation de main d'œuvre professionnelle et technologique, on croit cependant que la survalorisation de l'échelle locale par le capitalisme a l'effet de négliger les hiérarchies, la macroéconomie et les distinctes formes de pouvoir. Le resultat c'est la manquement de la promisse essentielle de l'expansion de ces Instituts.

This article analyzes the process of expansion of the Federal Institutes of Education, Science and Technology (FIs) in Brazil, stressing the relationship between local and national development. The Fis expansion project has socioeconomic development from local to national as its main objective, committing itself to regional growth by meeting regional social demands through the provision of professional and technological qualification. It is indicated, however, that the overvaluation of the locality, which has received increasing attention by the capital sectors, neglects factors that are exogenous to this scope, such as hierarchies, macroeconomics, and different forms of power, which influences the non-fulfilment of the central promise of this opening out process.

Este artículo, realiza un análisis sobre el proceso de expansión de los Institutos Federales de Educación, Ciencia y Tecnología - IFs - en el territorio Brasilero, presentando la relación entre el desarrollo nacional y el desarrollo local. El proyecto de expansión de los IFs se erige en la propuesta de desarrollo socioeconómico de la escala local para la nacional, comprometiéndose con el crecimiento regional en la atención de las demandas sociales locales por medio de la formación profesional y tecnológica. Se resalta, que la supervaloración de lo local, que recibe cada vez mayor atención del capital, descuida factores que son exógenos a este ámbito, como las jerarquías, la macroeconomía y las distintas formas de poder, lo que influencia el incumplimiento de la promesa central en este proceso de expansión.

\section{ÍNDICE}

Palavras-chave: expansão educacional, tensão interescalar, arranjos produtivos locais, desenvolvimento, Brasil.

Palabras claves: expansión de los IFs, tensión entre local y nacional, arreglos productivos locales, desarrollo, Brasil

Keywords: Federal Institute expansion, inter-scale tension, local productive arrangements, development, Brazil

Mots-clés: expansion éducationelle, tension inter-échelles, systèmes productifs locaux, dévellopement, Brésil.

\section{AUTOR}

\section{FERNANDA PAIXÃO DE SOUZA GOUVEIA}

Doutoranda do Programa de Políticas Públicas e Formação Humana (PPFH /UERJ). Técnica em Assuntos Educacionais no Instituto Federal de Educação, Ciência e Tecnologia do Rio de Janeiro (IFRJ) e professora colaboradora da Especialização em Educação de Jovens e Adultos do mesmo Instituto. Endereço eletrônico: fernanda.gouveia@ifrj.edu.br 